\title{
Postoperative $20 \%$ albumin vs standard care and acute kidney injury after high-risk cardiac surgery (ALBICS): study protocol for a randomised trial
}

Mayurathan Balachandran 1* (D, Piyusha Banneheke ${ }^{1}$, Adrian Pakavakis², Wisam Al-Bassam², Vineet Sarode ${ }^{3,4}$, Michael Rowland ${ }^{5}$ and Yahya Shehabi ${ }^{2,6}$

\begin{abstract}
Background: Acute kidney injury (AKI) is a common complication of cardiac surgery. Factors such as cardiopulmonary bypass, aortic cross-clamping and surgical stress may precipitate renal hypoperfusion and ischaemia, inflammation and oxidative stress are associated with development of AKI. Albumin's pharmacological properties and widespread availability have the potential to mitigate these factors. However, the effect of albumin on cardiac surgery-associated AKI is unknown.

Objective: To evaluate the impact of postoperative 20\% albumin infusion on kidney function after high-risk cardiac surgery.

Methods: We designed an open-label, multicentre, randomised controlled trial—the ALBICS study (ALBumin Infusion and acute kidney injury following Cardiac Surgery). A total of 590 patients undergoing high-risk cardiac surgery (combined procedure or estimated glomerular filtration rate (eGFR) $<60 \mathrm{~mL} / \mathrm{min} / 1.73 \mathrm{~m}^{2}$ ) will be enrolled into the study and randomly allocated to receive a postoperative $20 \%$ albumin infusion or standard care in a 1:1 ratio, stratified by centre and baseline renal function. The study fluid will be administered upon arrival in intensive care for $15 \mathrm{~h}$. Patients will be followed up until 28 days after surgery or until discharge from the hospital. The primary outcome is the proportion of patients who develop AKI in both groups. Secondary outcomes to be measured are proportions of AKI stage II and III, 28-day mortality, mechanical ventilation time and length of stay in intensive care and hospital.
\end{abstract}

Conclusion: This trial aims to determine if a postoperative infusion of concentrated albumin reduces the risk of AKI following high-risk cardiac surgery.

Trial registration: Australian New Zealand Clinical Trials Registry ACTRN12619001355167. Registered on 03 October 2019_retrospectively registered. https://www.anzctr.org.au/Trial/Registration/TrialReview.aspx?id=378383.

Keywords: Albumin, Cardiac surgery, Acute kidney injury, Intensive care

\footnotetext{
* Correspondence: mayurathan.balachandran@monashhealth.org

'School of Clinical Sciences at Monash Health, Monash University, Clayton, Victoria, Australia

Full list of author information is available at the end of the article
}

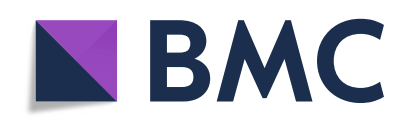

(- The Author(s). 2021 Open Access This article is licensed under a Creative Commons Attribution 4.0 International License, which permits use, sharing, adaptation, distribution and reproduction in any medium or format, as long as you give appropriate credit to the original author(s) and the source, provide a link to the Creative Commons licence, and indicate if changes were made. The images or other third party material in this article are included in the article's Creative Commons licence, unless indicated otherwise in a credit line to the material. If material is not included in the article's Creative Commons licence and your intended use is not permitted by statutory regulation or exceeds the permitted use, you will need to obtain permission directly from the copyright holder. To view a copy of this licence, visit http://creativecommons.org/licenses/by/4.0/. The Creative Commons Public Domain Dedication waiver (http://creativecommons.org/publicdomain/zero/1.0/) applies to the data made available in this article, unless otherwise stated in a credit line to the data. 


\section{Administrative information}

The order of the items has been modified to group similar items (see http://www.equator-network.org/ reporting-guidelines/spirit-2013-statement-definingstandard-protocol-items-for-clinical-trials/

\begin{tabular}{|c|c|}
\hline Title $\{1\}$ & $\begin{array}{l}\text { Postoperative } 20 \% \text { albumin vs standard } \\
\text { care and acute kidney injury after high- } \\
\text { risk cardiac surgery (ALBICS): study } \\
\text { protocol for a randomised trial }\end{array}$ \\
\hline Trial registration $\{2 \mathrm{a}$ and $2 \mathrm{~b}\}$. & $\begin{array}{l}\text { Australian New Zealand Clinical Trials } \\
\text { Registry, } 03 \text { October } 2019 \\
\text { (ACTRN1261900135516703) }\end{array}$ \\
\hline Protocol version $\{3\}$ & Version 2.11, 30 June 2021 \\
\hline Funding $\{4\}$ & $\begin{array}{l}\text { This study is internally funded by each } \\
\text { hospital's intensive care unit and/or } \\
\text { cardiothoracic department. }\end{array}$ \\
\hline Author details $\{5 \mathrm{a}\}$ & 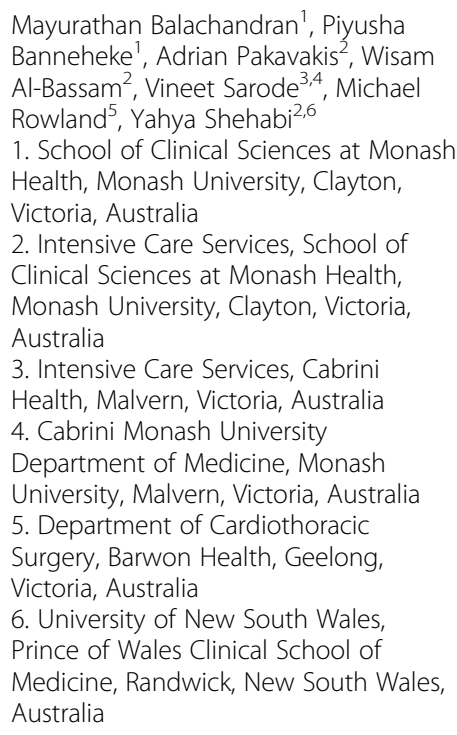 \\
\hline $\begin{array}{l}\text { Name and contact } \\
\text { information for the trial } \\
\text { sponsor }\{5 b\}\end{array}$ & $\begin{array}{l}\text { School of Clinical Sciences at Monash } \\
\text { HealthContact: Prof Yahya } \\
\text { ShehabiDirector of ICU Researchyahya. } \\
\text { shehabi@monashhealth.org }\end{array}$ \\
\hline Role of sponsor $\{5 c\}$ & $\begin{array}{l}\text { This is an investigator initiated study. } \\
\text { The study sponsor is the clinical school } \\
\text { where the chief investigator is } \\
\text { employed. The clinical school provides } \\
\text { administrative, logistic and other } \\
\text { supports that are required for this } \\
\text { study. }\end{array}$ \\
\hline
\end{tabular}

\section{Background and rationale $\{6 \mathbf{a}\}$}

Acute kidney injury is a well-recognised complication of cardiac surgery (CSA-AKI). A large retrospective cohort study of 25,086 patients reported CSA-AKI in $30 \%$ of patients [1]. This study also demonstrated odds ratios of in-hospital mortality equal to 3.17 in Acute Kidney Injury Network (AKIN) stage 1 and 43.77 in AKIN stage 3. Given that over one million patients undergo cardiac surgery each year, CSA-AKI presents a significant burden of disease [2].

\section{Pathophysiology and risk factors}

Current understanding of the pathophysiological mechanisms surrounding CSA-AKI are limited. There is unlikely to be a single mechanism responsible for AKI in these patients but instead a myriad of injurious pathways that take place in the perioperative period. Many of these pathways relate to renal perfusion, inflammation and oxidative stress (Fig. 1).

Cardiopulmonary bypass (CPB) is associated with postoperative renal injury, likely via a reduction in renal blood flow and glomerular filtration [3]. Non-pulsatile flow may also result in an imbalance between cortical and medullary perfusion [4]. Haemodilution is an inevitable consequence of $\mathrm{CPB}$ and has been identified as an independent predictor of CSA-AKI [5-7]. The renal medulla and corticomedullary junction are particularly vulnerable to these changes given their relative hypoxia in comparison to other tissues $[8,9]$. Prolonged hypoperfusion precipitates ischaemic changes such as inflammatory cell infiltration, cell contraction and necrosis [10]. Other operative risk factors include aortic cross-clamp time, blood transfusion, inotrope requirements and the complexity of the procedure performed $[11,12]$.

Cardiac surgery results in increased levels of proinflammatory cytokines, notably interleukin (IL)- 6 and tumour necrosis factor (TNF)- $\alpha$ [13] with increased risk of AKI after cardiac surgery [14-16]. Subsequent activation of macrophages, neutrophils and lymphocytes lead to renal parenchymal infiltration and development of AKI $[17,18]$.

\section{Hypoalbuminaemia and cardiac surgery}

Hypoalbuminaemia is common after cardiac surgery. A large observational study $(n=2818)$ found that $94 \%$ of patients with normal preoperative serum albumin levels developed hypoalbuminaemia at $24 \mathrm{~h}$ after cardiac surgery, where the risk of AKI approximately doubled with each $5 \mathrm{~g} / \mathrm{l}$ reduction [19].

In separate meta-analyses of 90 cohort studies and 9 RCTs totalling 291,433 and 535 acutely ill patients, Vincent et al. found that a $10 \mathrm{~g} / \mathrm{l}$ reduction in serum albumin correlated with an increased odds of mortality and morbidity of $116 \%$ and $52 \%$ after cardiac surgery [20]. The analysis of randomised trials also suggests that albumin supplementation to maintain serum levels greater than $30 \mathrm{~g} / \mathrm{l}$ decreases the rate of complications. These results contend that hypoalbuminaemia is common after cardiac surgery and its correction may prevent AKI.

Albumin administration may not be useful in all critically ill populations. A recently published randomised trial of 828 hypoalbuminaemic patients with acute complications of decompensated cirrhosis randomised patients to receive daily $20 \%$ albumin infusions titrated to the degree of hypoalbuminaemia 


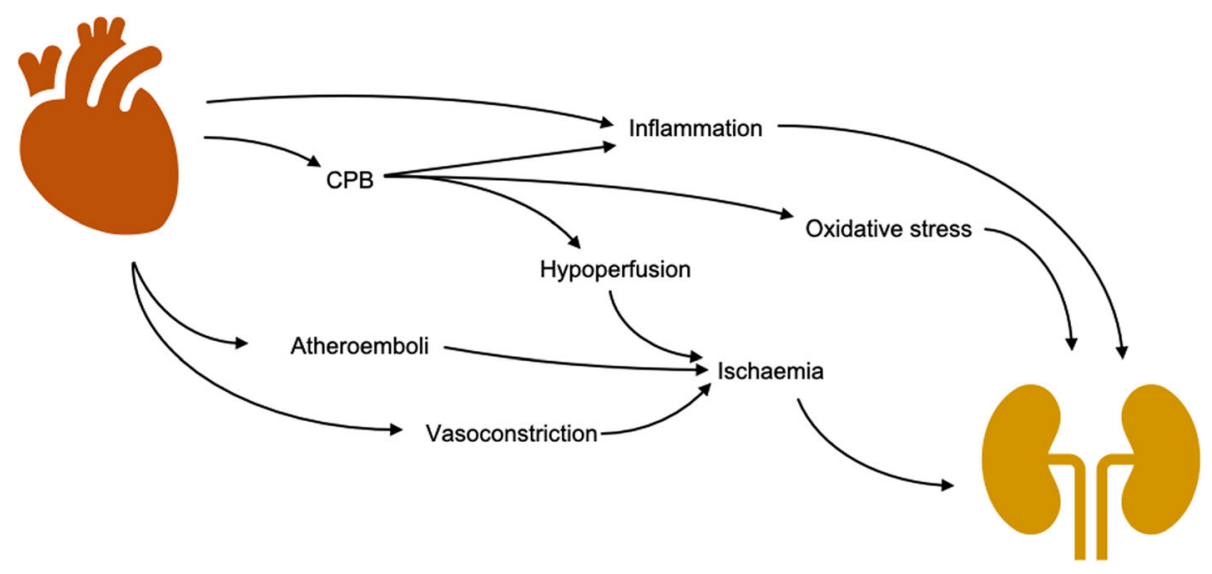

Fig. 1 Pathophysiology of CSA-AKI

[21]. Despite increasing serum albumin concentrations, albumin administration failed to improve outcomes with respect to in-hospital kidney dysfunction and mortality at 28 days, 3 months and 6 months.

\section{Nephroprotective properties of albumin}

Albumin may have nephroprotective effects via different mechanisms. Albumin infusion reduces fluid overload which is an independent risk factor for AKI in critically ill patients [22-24]. A rise in venous pressure and subsequent renal interstitial oedema impair glomerular filtration [25] and may reduce cortical oxygen pressures [26].

The HAS FLAIR trial found similar results comparing $20 \%$ albumin and crystalloid fluid bolus therapy over the first $24 \mathrm{~h}$ after cardiac surgery (median $1100 \mathrm{ml}$ vs 1970 $\mathrm{ml}, p=0.001, n=100$ ) [27]. Additionally, the SWIPE trial found that in a sample of $321 \mathrm{ICU}$ patients, half of whom had undergone cardiac surgery, 20-25\% albumin preparations reduced fluid requirements in the first $48 \mathrm{~h}$ compared to $4-5 \%$ albumin preparations (median 3429 $\mathrm{ml}$ vs $4217 \mathrm{ml}, p=0.06$ ) [28].

Injury to the endothelium contributes to the development of AKI. Endothelial damage increases leukocyte adherence, platelet aggregation, vasoconstriction and podocyte dysfunction [29]. Loss of the glycocalyx is thought to relate to microthrombi, ischaemia reperfusion injury, oxidative stress and systemic inflammation; all of which may occur following CPB [10, 30, 31]. Administration of albumin protects the glycocalyx. In animal models, administration of albumin resulted in reduced measures of glycocalyx dysfunction $[32,33]$.

Albumin contributes to antioxidant activity in plasma. Over $70 \%$ of free radical neutralisation is attributable to albumin [34]. This property is predominantly due to its abundance and the existence of a thiol group in the cysteine-34 position of its molecular structure. Thiols are known for their reaction with, and 'trapping' of, reactive oxygen species. In healthy subjects, $70-80 \%$ of serum albumin is reduced at the cysteine- 34 thiol, while an additional $25 \%$ may be oxidised further [35, 36].

\section{Clinical trials of albumin and cardiac surgery}

In the first and only clinical trial investigating albumin in this way, Lee et al. randomised 220 patients with undergoing off-pump cardiac surgery to receive either preoperative $20 \%$ albumin or saline [37]. This doubleblind study included patients with preoperative serum albumin level less than $40 \mathrm{~g} / \mathrm{l}$. The volume of fluid administered varied between 100 and $300 \mathrm{ml}$ and was titrated to each patient's preoperative serum albumin level. Albeit limitations, the trial reported reduced risk of AKI by Kidney Disease: Improving Global Outcomes (KDIGO) [38] (RR $=0.533, p=0.048)$ and Acute Kidney Injury Network (AKIN) criteria $(\mathrm{RR}=0.557, p=0.031)$ with albumin administration.

There is insufficient scientific literature to determine the utility of exogenous albumin to prevent CSA-AKI. More clinical trials are needed in this area.

\section{Objectives $\{7\}$}

We hypothesise that an infusion of $20 \%$ albumin will reduce the proportion of patients who develop postoperative AKI after high-risk cardiac surgery, when compared to standard care.

The objective of this study is to evaluate the impact of postoperative $20 \%$ albumin infusion on kidney function after high-risk cardiac surgery.

\section{Trial design $\{\mathbf{8}\}$}

The ALBICS (ALBumin Infusion and acute kidney injury following Cardiac Surgery) study is a multicentre, 
parallel-group, open-label, prospective, randomised controlled, superiority trial.

\section{Methods: participants, interventions and outcomes Study setting $\{9\}$}

Patients will be recruited at the following Australian hospitals: Monash Medical Centre, Cabrini Hospital, University Hospital Geelong, Prince of Wales Hospital, Prince of Wales Private Hospital and the Austin Hospital.

\section{Eligibility criteria \{10\}}

To be included in the study, patients must meet all of the following inclusion criteria:

- Aged 18 years or older;

- Have undergone cardiac surgery;

- At least one of the following:

i. Estimated glomerular filtration rate $(\mathrm{eGFR})<60$ $\mathrm{mL} / \mathrm{min} / 1.73 \mathrm{~m}^{2}$, or

ii. Have had a combined valve and coronary procedure, or

iii. Two or more valve procedures, or

iv. Surgery involving the thoracic aorta.

Patients meeting any of the following exclusion criteria will be excluded from the study:

- eGFR $<15 \mathrm{~mL} / \mathrm{min} / 1.73 \mathrm{~m}^{2}$,

- Serum albumin $<20 \mathrm{~g} / \mathrm{l}$,

- Dialysis dependence,

- Kidney transplant,

- Undergone off-pump cardiac surgery,

- Requiring extra-corporeal life support or ventricular assist device immediately postoperative,

- Jehovah's Witness.

\section{Who will take informed consent? \{26a\}}

A study investigator will obtain informed consent from each participant prior to enrolment in this study. The investigator will discuss the risks and benefits of participation and will check that the patient comprehends the information provided. Consent will be voluntary and free from coercion.

\section{Additional consent provisions for collection and use of participant data and biological specimens $\{26 b\}$ \\ Not applicable.}

\section{Interventions}

Explanation for the choice of comparators $\{6 \mathrm{~b}\}$

Patients will be randomly allocated to either the intervention group (albumin 20\% and standard care) or the comparator group (standard care only). Standard care was chosen as an appropriate comparator given that the intervention is proposed as an adjunct to routine care.

\section{Intervention description $\{11 \mathrm{a}\}$}

Patients randomised to the intervention arm will receive an intravenous infusion of $20 \%$ albumin for $15 \mathrm{~h}$ at 20 $\mathrm{ml} / \mathrm{h}$ as soon as possible after ICU admission, where the time to initiation of infusion does not exceed $6 \mathrm{~h}$.

Patients randomised to the standard care arm will not receive any $20 \%$ albumin for the first $24 \mathrm{~h}$ of ICU admission.

\section{Relevant concomitant care permitted or prohibited during the trial $\{11 \mathrm{~d}\}$}

Both treatment groups will receive standard care as per the clinician in charge. This includes any background treatments considered routine care such as vasopressors, inotropes, ventilation and initiation of dialysis. Administration of $4 \%$ albumin will not be restricted.

\section{Criteria for discontinuing or modifying allocated interventions $\{11 \mathrm{~b}\}$}

For those randomised to receive $20 \%$ albumin, the infusion may be ceased if the patient develops an allergic reaction or fluid overload (shortness of breath, increased oxygen requirements).

For those randomised to receive standard care, 20\% albumin may be administered within the first $24 \mathrm{~h}$ if it is deemed clinically indicated. These decisions will be at the discretion of the clinician in charge.

\section{Strategies to improve adherence to interventions $\{11 \mathrm{c}\}$}

The design for the ALBICS study will be presented to staff at each participating site, with input from intensive care specialists, cardiac surgeons and cardiac anaesthetists. These meetings will improve consistency of protocol implementation. Other measures include presentations and visual information provided to clinical staff to reduce the risk of inadvertent protocol deviation.

\section{Provisions for post-trial care $\{30\}$}

All patients enrolled in this trial will receive standard postoperative surgical care beyond $24 \mathrm{~h}$. Patients will be followed as per the study protocol.

\section{Outcomes $\{12\}$}

The primary outcome is the proportion of patients that develop AKI within hospital stay up to Day 28 postenrolment. AKI is defined by creatinine-based KDIGO criteria (Table 1 Pathophysiology of CSA-AKI) [38]. Patients after cardiac surgery often have polyuria in the first few hours after surgery and they are frequently given diuretic therapy after day 1 postoperatively. For 
Table 1 KDIGO creatinine-based criteria for diagnosis and staging of AKI

\begin{tabular}{|c|c|}
\hline Stage & Serum creatinine \\
\hline । & $\begin{array}{l}1.5-1.9 \text { times baseline within } 7 \text { days; or } \\
\geq 26.5 \mu \mathrm{mol} / \mathrm{l}(\geq 0.3 \mathrm{mg} / \mathrm{dl}) \text { increase within } 48 \mathrm{~h}\end{array}$ \\
\hline$\|$ & 2.0-2.9 times baseline within 7 days \\
\hline III & $\begin{array}{l}\geq 3.0 \text { times baseline within } 7 \text { days; or } \\
\text { Increase to } \geq 353.6 \mu \mathrm{mol} / \mathrm{l}(\geq 40 \mathrm{mg} / \mathrm{dl}) \text {; or } \\
\text { Initiation of renal replacement therapy }\end{array}$ \\
\hline
\end{tabular}

this reason, urine output may not a be a reliable measure of AKI.

Secondary and tertiary outcomes are described in Table 2. These outcomes were chosen as appropriate measures of acute deterioration or recovery, and the haemodynamic effects of albumin.

\section{Participant timeline $\{13\}$}

Patients will be followed up until the 28th day postenrolment or hospital discharge, whichever occurs first. Data collected will be restricted to the parameters that are necessary to define clinical characteristics and will be obtained from routine laboratory investigations and hospital records (Fig. 2). This includes baseline demographics, outcome measures, physiological parameters, operative data, therapeutic interventions, death and other adverse events.

\section{Sample size $\{14\}$}

The sample size for the study was determined by a priori power analysis. The anticipated incidence of AKI in the comparator group was based upon a cohort of over 25,000 patients that reported AKI in 30\% of patients undergoing cardiac surgery [1]. Based on this estimate, the inclusion of 590 patients will achieve $80 \%$ power to detect a $10 \%$ absolute risk reduction in the risk of AKI (2-sided $p=0.05$ ).

\section{Recruitment $\{15\}$}

Recruitment will take place at metropolitan teaching hospitals that see a large number of cardiac cases. This will allow sufficient enrolment to reach the target sample size in a timely manner.

\section{Assignment of interventions Sequence generation $\{16 \mathrm{a}\}$}

A permuted block, computer-generated, randomisation sequence with fixed block size, stratified by hospital and eGFR $\left(<60 \mathrm{~mL} / \mathrm{min} / 1.73 \mathrm{~m}^{2}\right.$ or $\left.>60 \mathrm{~mL} / \mathrm{min} / 1.73 \mathrm{~m}^{2}\right)$ will be used to allocate participants in a 1:1 ratio.

\section{Concealment mechanism $\{16 \mathrm{~b}\}$}

Patients will be allocated using REDCap (Research Electronic Data Capture), a computer-based software for data collection. REDCap will use the prepared randomisation schedule to determine the allocation of the participant in a traceable manner, such that the treatment group is not knowable prior to allocation and cannot be changed after it. While blinding clinicians to treatment allocation is desirable, it is not deemed feasible for this study. We minimise bias through allocation concealment and evaluation of objective laboratory-based data.

\section{Implementation $\{16 \mathrm{c}\}$}

The allocation sequence will be generated by a person not involved with enrolment or future analysis. Participants will be screened and randomised on admission to intensive care by a site investigator or member of research support staff.

\section{Blinding \{17a\}}

While blinding is a desirable feature of clinical trials, the study outcomes are distant from the intervention and the open-label design is unlikely to influence the outcome at 28 days.

Table 2 Study outcomes

Primary outcome

Secondary outcomes
In-hospital AKI Stage I, II or III (proportion of patients)

In-hospital AKI stage II and III (proportion of patients)

In-hospital mortality

ICU LOS (hours)

Hospital LOS (days)

Ventilation time (hours)

Tertiary outcomes
Peak SCr $(\mu \mathrm{mol} / \mathrm{l})$

Serum albumin at $24 \mathrm{~h}(\mathrm{~g} / \mathrm{l})$

Serum $\mathrm{Hb}$ at ICU discharge $(\mathrm{g} / \mathrm{l})$

Proportion of patients needing inotrope and/or vasopressor therapy Net fluid balance at $48 \mathrm{~h}(\mathrm{ml})$

Quantity of RBCs transfused over first $48 \mathrm{~h}(\mathrm{ml})$

Initiation of CRRT 


\begin{tabular}{|c|c|c|c|c|c|c|c|c|c|}
\hline \multicolumn{10}{|c|}{ STUDY PERIOD } \\
\hline & \multirow{2}{*}{$\begin{array}{c}\text { Enrolment } \\
-t_{1}\end{array}$} & \multirow{2}{*}{$\begin{array}{c}\text { Allocation } \\
0\end{array}$} & \multicolumn{6}{|c|}{ Post-allocation } & \multirow{2}{*}{$\begin{array}{c}\text { Day } 28 \text { or } \\
\text { discharge } \\
t_{x}\end{array}$} \\
\hline TIMEPOINT & & & $t_{1}$ & $t_{2}$ & $t_{3}$ & $t_{4}$ & etc. & ICU discharge & \\
\hline \multicolumn{10}{|l|}{ ENROLMENT: } \\
\hline Eligibility screen & $X$ & & & & & & & & \\
\hline Informed consent & $X$ & & & & & & & & \\
\hline Cardiac surgery & $X$ & & & & & & & & \\
\hline Allocation & & $X$ & & & & & & & \\
\hline \multicolumn{10}{|l|}{ INTERVENTIONS: } \\
\hline $20 \%$ albumin & & & \multicolumn{2}{|c|}{15 hours } & & & & & \\
\hline Routine care & & & \multicolumn{2}{|c|}{24 hours } & & & & & \\
\hline \multicolumn{10}{|l|}{ ASSESSMENTS: } \\
\hline \multicolumn{10}{|l|}{$\begin{array}{l}\text { Demographics, } \\
\text { LVEF, } \\
\text { medications, Hct, } \\
\text { eGFR, APACHE III } \\
\text { \& risk of death, } \\
\text { operative data }\end{array}$} \\
\hline Serum Hb & $X$ & & & & & & & $X$ & \\
\hline Serum albumin & $X$ & & $X$ & $X$ & $X$ & $X$ & etc. & & $X$ \\
\hline $\mathrm{SCr}$ & $X$ & & $X$ & X & $X$ & $X$ & etc. & & \\
\hline $\begin{array}{l}\text { Duration of } \\
\text { ventilation, } \\
\text { initiation of IV } \\
\text { frusemide or non- } \\
\text { loop diuretics, } \\
\text { CRRT, } \\
\text { Reoperation, ICU } \\
\text { readmission }\end{array}$ & & & $X$ & $X$ & $x$ & $X$ & etc. & & \\
\hline $\begin{array}{l}\text { Total and type of } \\
\text { fluid input/output }\end{array}$ & $\begin{array}{l}\text { During } \\
\text { surgery }\end{array}$ & & & h & & & & & \\
\hline $\begin{array}{l}\text { Inotrope and } \\
\text { vasopressors }\end{array}$ & $\begin{array}{l}\text { During } \\
\text { surgery }\end{array}$ & & $X$ & $X$ & $X$ & $X$ & etc. & & \\
\hline $\begin{array}{l}\text { ICU mortality, ICU } \\
\text { discharge } \\
\text { date/time }\end{array}$ & & & & & & & & $X$ & \\
\hline $\begin{array}{l}\text { Hospital } \\
\text { discharge } \\
\text { date/time, hospital } \\
\text { mortality }\end{array}$ & & & & & & & & & $X$ \\
\hline
\end{tabular}

Fig. 2 Data collection timeline (SPIRIT figure). CRRT, continuous renal replacement therapy; eGFR, estimated glomerular filtration rate; Hb, haemoglobin; Hct, haematocrit; ICU, intensive care unit; LVEF, left ventricular ejection fraction; SCr, serum creatinine 
Procedure for unblinding $\{17 b\}$

Not applicable.

\section{Data collection and management}

Plans for assessment and collection of outcomes $\{18 \mathrm{a}\}$

All study data will be collected by research staff at each site using an electronic case report form and stored in a password-protected, traceable, database managed by Monash University. All parameters are defined in a data dictionary detailing the way in which data should be collected. The central coordinating investigators will ensure site visits for data monitoring, timely resolution of queries and correction of errata during quality control checks.

\section{Plans to promote participant retention and complete follow-up $\{18 b\}$}

The intervention is to be administered soon after ICU admission and will last a short duration of time, likely while participants are unconscious. Patients will be approached once conscious and practical to do so, to inform them of study progress and follow-up required. Obtaining data from medical records and laboratory data will ensure complete follow-up.

\section{Data management $\{19\}$}

Study data was collected and managed using REDCap electronic data capture tool hosted and managed by Helix (Monash University) [39, 40]. REDCap is a secure, webbased software platform designed to support data capture for research studies, providing [1] an intuitive interface for validated data capture [2]; audit trails for tracking data manipulation and export procedures [3]; automated export procedures for seamless data downloads to common statistical packages; and [4] procedures for data integration and interoperability with external sources.

\section{Confidentiality $\{27\}$}

Wherever possible, identifying information will be removed. Only de-identified data will be entered into the case report form. Identifying documents such as consent forms will be kept in locked rooms that may only be accessed by authorised personnel.

Plans for collection, laboratory evaluation and storage of biological specimens for genetic or molecular analysis in this trial/future use $\{33\}$

Not applicable. This study evaluates data collected via routine laboratory investigation.

\section{Statistical methods}

Statistical methods for primary and secondary outcomes \{20a\}

Normality of continuous variables will be assessed and log-transformed where appropriate. Equality of variance for normally distributed variables will be assessed using Levene's test. Between-group comparisons will be performed using chi-squared tests for equal proportion, Student's $t$ test for continuous variables with equal variance, Welch's $t$ test for continuous variables with unequal variance, and Mann-Whitney $U$ test otherwise. Categorical variables will be described as frequency with proportions (\%). Continuous variables will be expressed as mean \pm standard deviation if normally distributed, and median with interquartile range if not normally distributed. Analysis will be performed using $\mathrm{R}$ version 4.0.2 ( $\mathrm{R}$ Foundation for Statistical Computing, Vienna, Austria).

Methods for additional analyses $\{20 \mathrm{~b}\}$

A subgroup analysis will be performed in patients with and without baseline renal insufficiency (eGFR $<60 \mathrm{~mL} /$ $\min / 1.73 \mathrm{~m}^{2}$ or $\geq 60 \mathrm{~mL} / \mathrm{min} / 1.73 \mathrm{~m}^{2}$ ).

Interim analyses $\{21 \mathrm{~b}\}$

An interim analysis is not planned.

Methods in analysis to handle protocol non-adherence and any statistical methods to handle missing data $\{20 \mathrm{c}\}$ Data will be analysed using an intention-to-treat methodology. A per-protocol sensitivity analysis will also be conducted. Ongoing site education would reduce the risk of protocol deviation. We will adjust for missing data using multiple imputation.

\section{Oversight and monitoring}

Composition of the coordinating centre and trial steering committee $\{5 \mathrm{~d}\}$

The trial steering committee is composed of investigators from the departments of cardiothoracic surgery and intensive care. The chair of the steering committee, through the School of Clinical Sciences at Monash Health, will be coordinating this study.

Composition of the data monitoring committee, its role and reporting structure $\{21 \mathrm{a}\}$

Albumin administration is considered part of routine postoperative care after cardiac surgery. In addition, the open-label design will allow the assignment of adverse events to the intervention. Serious adverse events will be reviewed regularly by the study steering committee and reported to the ethics committee.

\section{Adverse event reporting and harms $\{22\}$}

Adverse events will be collected in accordance with the Monash Health Human Research Ethics Committee guidelines. Serious adverse reactions will be reported to the institutional research support services at each site. 
Significant safety issues will be reported to the Monash Health Human Research Ethics Committee.

\section{Frequency and plans for auditing trial conduct $\{23\}$}

After each site is activated and has enrolled five patients, site monitoring of the consenting process, protocol adherence and data collection will be conducted. At the end of this study, all sites will be monitored for protocol adherence and completion of data collection.

\section{Plans for communicating important protocol amendments to relevant parties $\{25\}$}

Protocol amendments will be promptly distributed to all relevant parties via the appropriate channels, for example by email or formal ethics review.

\section{Dissemination plans $\{31$ a}

The study will be published in the name of the individual investigators and in the group name 'ALBICS study investigators'. Full credit will be given to all collaborating investigators, research staff and institutions. All authors will comply with the internationally agreed upon requirements for authorship and will approve the manuscript before submission.

The final results will be presented at one or more major scientific meetings and will be published in a peer-reviewed scientific journal that discusses care of critically ill patients. We will ensure that results are available to study participants and for translation to intensive care with concurrent recommendations for change in practice based on the study findings.

\section{Conclusions}

Acute kidney injury after cardiac surgery is common. Cardiopulmonary bypass appears to be an important factor and may precipitate AKI through various mechanisms related to renal hypoperfusion, inflammation and oxidative stress. Albumin's oncotic and pharmacological properties demonstrate its potential benefit for the prevention of CSA-AKI. A large, multicentre randomised trial is needed to determine this definitively. The ALBICS study is designed to answer this question.

\section{Trial status}

Recruitment began on 08 July 2019. As at October 2020, 25 patients have been enrolled in the ALBICS study. The COVID-19 pandemic has had a significant impact on study progress, having halted recruitment at all participating sites. The study recommenced recruitment on 19 July 2021 and we expect the trial to reach completion by the end of 2023. Working protocol version 2.11, 30 June 2021. A protocol amendment was approved in July 2021.

\section{Abbreviations}

AKI: Acute kidney injury; AKIN: Acute Kidney Injury Network;

CPB: Cardiopulmonary bypass; CSA-AKI: Cardiac surgery-associated acute kidney injury; eGFR: Estimated glomerular filtration rate; ICU: Intensive care unit; IL: Interleukin; KDIGO: Kidney Disease: Improving Global Outcomes; mRNA: Messenger ribonucleic acid; REDCap: Research Electronic Data Capture; RCT: Randomised controlled trial; SBP: Spontaneous bacterial peritonitis; SPIRIT: Standard Protocol Items: Recommendations for Interventional Trials; TNF: Tumour necrosis factor

\section{Acknowledgements}

The authors would like to acknowledge the contributions of all ALBICS investigators:

Monash Medical Centre: Mayurathan Balachandran, Piyusha Banneheke, Adrian Pakavakis, Wisam Al-Bassam, Dhiraj Bhatia, Julian Smith, Yahya Shehabi University Hospital Geelong: Michael Rowland, Xiao Bo Zhang, Cheng Hon Yap, Marita Turner, Kathleen DenDryver, Neil Orford

Cabrini Hospital: Vineet Sarode, Shannon Simpson

Prince of Wales Hospital (public and private): Yahya Shehabi, David Bihari, David Collins

Plans to give access to the full protocol, participant-level data and statistical code $\{31 \mathrm{c}\}$

The full protocol, participant-level dataset and statistical code will be available in accordance with Monash University data sharing protocols.

\section{Authors' contributions $\{31 \mathrm{~b}\}$}

Authors MB, PB, AP, WA and YS contributed to the conception and design of this study. YS is the Coordinating Principal Investigator. AP, VS, MR and YS are the Site Principal Investigators at Monash Health, Cabrini Health, Barwon Health and Prince of Wales Hospital. All authors are involved with trial coordination. All authors read and approved the final manuscript.

\section{Funding $\{4\}$}

This study will be internally funded by the intensive care or cardiothoracic department at each site.

Availability of data and materials $\{29\}$

The datasets for the completed study will be available according to Monash University data sharing protocols. The authors have no contractual agreements to disclose that would limit such access.

\section{Declarations}

Ethics approval and consent to participate $\{24\}$

Ethics approval was granted by the Monash Health Human Research Ethics Committee (Review reference: HREC/51818/MonH-2019-174088(v3)) and the Monash University Human Research Ethics Committee (Review reference: 2019-20388-31894). Ethics approval and local site governance was obtained at all participating sites before study commencement. Informed consent will be obtained from all participants.

Consent for publication $\{32\}$

Model consent forms are available upon request.

Competing interests $\{28\}$

The authors declare that they have no competing interests.

\section{Author details}

${ }^{1}$ School of Clinical Sciences at Monash Health, Monash University, Clayton, Victoria, Australia. Intensive Care Services, School of Clinical Sciences at Monash Health, Monash University, Clayton, Victoria, Australia. Intensive Care Services, Cabrini Health, Malvern, Victoria, Australia. ${ }^{4}$ Cabrini Monash University Department of Medicine, Monash University, Malvern, Victoria, Australia. ${ }^{5}$ Department of Cardiothoracic Surgery, Barwon Health, Geelong, Victoria, Australia. ${ }^{6}$ University of New South Wales, Prince of Wales Clinical School of Medicine, Randwick, New South Wales, Australia. 
Received: 11 April 2021 Accepted: 6 August 2021

Published online: 21 August 2021

\section{References}

1. Robert AM, Kramer RS, Dacey L, Charlesworth DC, Leavitt BJ, Helm RE, et al. Cardiac surgery-associated acute kidney injury: a comparison of two consensus criteria. Ann Thorac Surg. 2010;90(6):1939-43. https://doi.org/10.1 016/j.athoracsur.2010.08.018.

2. Lee JJ, Park NH, Lee KS, Chee HK, Sim SB, Kim MJ, et al. Projections of demand for cardiovascular surgery and supply of surgeons. Korean J Thorac Cardiovasc Surg. 2016;49(Suppl 1):S37-43. https://doi.org/10.5090/kjtcs.201 6.49.S1.S37.

3. Fischer UM, Weissenberger WK, Warters RD, Geissler HJ, Allen SJ, Mehlhorn U. Impact of cardiopulmonary bypass management on postcardiac surgery renal function. Perfusion. 2002;17(6):401-6. https://doi.org/10.1191/02676591 02pf610oa.

4. Alghamdi AA, Latter DA. Pulsatile versus nonpulsatile cardiopulmonary bypass flow: an evidence-based approach. J Card Surg. 2006;21(4):347-54. https://doi.org/10.1111/j.1540-8191.2006.00269.x.

5. Karkouti K, Beattie WS, Wijeysundera DN, Rao V, Chan C, Dattilo KM, et al. Hemodilution during cardiopulmonary bypass is an independent risk factor for acute renal failure in adult cardiac surgery. J Thorac Cardiovasc Surg. 2005;129(2):391-400. https://doi.org/10.1016/j.jtcvs.2004.06.028.

6. Mehta RH, Castelvecchio S, Ballotta A, Frigiola A, Bossone E, Ranucci M. Association of gender and lowest hematocrit on cardiopulmonary bypass with acute kidney injury and operative mortality in patients undergoing cardiac surgery. Ann Thorac Surg. 2013;96(1):133-40. https://doi.org/10.101 6/j.athoracsur.2013.03.033.

7. Ranucci M, Aloisio T, Carboni G, Ballotta A, Pistuddi V, Menicanti L, et al. Acute kidney injury and hemodilution during cardiopulmonary bypass: a changing scenario. Ann Thorac Surg. 2015;100(1):95-100. https://doi.org/1 0.1016/j.athoracsur.2015.02.034.

8. Aperia AC. The influence of arterial PO2 on renal tissue PO2. Acta Physiol Scand. 1969;75(3):353-9. https://doi.org/10.1111/j.1748-1716.1969.tb04388.x.

9. Liss P, Nygren A, Erikson U, Ulfendahl HR. Injection of low and iso-osmolar contrast medium decreases oxygen tension in the renal medulla. Kidney Int. 1998;53(3):698-702. https://doi.org/10.1046/j.1523-1755.1998.00811.x.

10. Bonventre JV, Yang L. Cellular pathophysiology of ischemic acute kidney injury. J Clin Invest. 2011;121(11):4210-21. https://doi.org/10.1172/JCl45161.

11. Doddakula K, Al-Sarraf N, Gately K, Hughes A, Tolan M, Young V, et al. Predictors of acute renal failure requiring renal replacement therapy post cardiac surgery in patients with preoperatively normal renal function. Interact Cardiovasc Thorac Surg. 2007:6(3):314-8. https://doi.org/10.1510/icvts.2006.148874.

12. Parolari A, Pesce $L L$, Pacini D, Mazzanti V, Salis S, Sciacovelli C, et al. Risk factors for perioperative acute kidney injury after adult cardiac surgery: role of perioperative management. Ann Thorac Surg. 2012;93(2):584-91. https:// doi.org/10.1016/j.athoracsur.2011.09.073.

13. Garau I, März A, Sehner S, Reuter DA, Reichenspurner H, Zöllner C, et al. Hemadsorption during cardiopulmonary bypass reduces interleukin 8 and tumor necrosis factor a serum levels in cardiac surgery: a randomized controlled trial. Minerva Anestesiol. 2019;85(7):715-23. https://doi.org/10.23 736/S0375-9393.18.12898-7

14. Zhang WR, Garg AX, Coca SG, Devereaux PJ, Eikelboom J, Kavsak P, et al. Plasma IL-6 and IL-10 concentrations predict AKI and long-term mortality in adults after cardiac surgery. J Am Soc Nephrol. 2015;26(12):3123-32. https:// doi.org/10.1681/ASN.2014080764.

15. El Azab SR, Doha N, Rady A, El-Sayed AE, Abd-Rabo M. The cytokine balance during $C A B G$ surgery with and without cardiopulmonary bypass. Egypt J Anaesthesia. 2010;26(4):281-6. https://doi.org/10.1016/j.egja.2010.05.003.

16. Wei C, Li L, Kim IK, Sun P, Gupta S. NF-kB mediated miR-21 regulation in cardiomyocytes apoptosis under oxidative stress. Free Radic Res. 2014;48(3): 282-91. https://doi.org/10.3109/10715762.2013.865839.

17. O'Neal JB, Shaw AD, Billings FT. Acute kidney injury following cardiac surgery: Current understanding and future directions. Crit Care. 2016;20:1-9.

18. Wang Y, Bellomo R. Cardiac surgery-associated acute kidney injury: risk factors, pathophysiology and treatment. Nat Rev Nephrol. 2017;13(11):697711. https://doi.org/10.1038/nrneph.2017.119.

19. Berbel-Franco D, Lopez-Delgado JC, Putzu A, Esteve F, Torrado H, Farrero E, et al. The influence of postoperative albumin levels on the outcome of cardiac surgery. J Cardiothorac Surg. 2020;15(1):78. https:/doi.org/10.1186/s13019-020-01133-y.
20. Vincent JL, Dubois MJ, Navickis RJ, Wilkes MM. Hypoalbuminemia in acute illness: is there a rationale for intervention? A meta-analysis of cohort studies and controlled trials. Ann Surg. 2003;237(3):319-34.

21. China L, Freemantle N, Forrest E, Kallis $Y$, Ryder SD, Wright G, et al. A randomized trial of albumin infusions in hospitalized patients with cirrhosis. N Engl J Med. 2021;384(9):808-17. https://doi.org/10.1056/NEJMoa2022166.

22. Wang N, Jiang L, Zhu B, Wen Y, Xi X-M. Beijing Acute Kidney Injury Trial W. Fluid balance and mortality in critically ill patients with acute kidney injury: a multicenter prospective epidemiological study. Critical Care (London, England). 2015;19:371.

23. Selewski DT, Goldstein SL. The role of fluid overload in the prediction of outcome in acute kidney injury. Pediatr Nephrol. 2018;33(1):13-24. https:// doi.org/10.1007/s00467-016-3539-6.

24. Glassford NJ, Bellomo R. Acute kidney injury: how can we facilitate recovery? Curr Opin Crit Care. 2011;17(6):562-8. https://doi.org/10.1097/ Mcc.0b013e32834cd334.

25. Winton FR. The influence of venous pressure on the isolated mammalian kidney. J Physiol. 1931;72(1):49-61. https://doi.org/10.1113/jphysiol.1931.sp002761.

26. Lent $\mathrm{V}$, Kessler M. Cortical oxygen pressure during acute venous kidney obstruction. Urol Res. 1982;10(1):7-11. https://doi.org/10.1007/BF00256517.

27. Wigmore GJ, Anstey JR, St. John A, Greaney J, Morales-Codina M, Presneill $J$, et al. 20\% human albumin solution fluid bolus administration therapy in patients after cardiac surgery (the HAS FLAIR Study). J Cardiothorac VasC Anesth. 2019;33(11):2920-7. https://doi.org/10.1053/j.jvca.2019.03.049.

28. Mårtensson J, Bihari S, Bannard-Smith J, Glassford NJ, Lloyd-Donald P, Cioccari L, et al. Small volume resuscitation with $20 \%$ albumin in intensive care: physiological effects. Intensive Care Med. 2018;44(11):1797-806. https://doi.org/10.1007/s00134-018-5253-2.

29. Li L, Bonventre JV. Endothelial glycocalyx: not just a sugar coat. Am J Respir Crit Care Med. 2016;194(4):390-3. https://doi.org/10.1164/rccm.201603-0624ED.

30. Myers GJ, Wegner J. Endothelial glycocalyx and cardiopulmonary bypass. J Extra Corpor Technol. 2017;49(3):174-81.

31. Rabelink TJ, de Zeeuw D. The glycocalyx--linking albuminuria with renal and cardiovascular disease. Nat Rev. 2015;11(11):667-76.

32. Jacob M, Bruegger D, Rehm M, Welsch U, Conzen P, Becker BF. Contrasting effects of colloid and crystalloid resuscitation fluids on cardiac vascular permeability. Anesthesiology. 2006;104(6):1223-31. https://doi.org/10.1097/ 00000542-200606000-00018.

33. Jacob M, Paul O, Mehringer L, Chappell D, Rehm M, Welsch U, et al. Albumin augmentation improves condition of guinea pig hearts after $4 \mathrm{hr}$ of cold ischemia. Transplantation. 2009;87(7):956-65. https://doi.org/10.1097/ TP.0b013e31819c83b5.

34. Roche M, Rondeau P, Singh NR, Tarnus E, Bourdon E. The antioxidant properties of serum albumin. FEBS Lett. 2008;582(13):1783-7. https://doi. org/10.1016/j.febslet.2008.04.057.

35. Era S, Kazuo K, Imai H, Nakamura K, Hayashi T, Sogami M. Age-related change in redox state of human serum albumin. Biochim Biophys Acta Protein Struct Mol Enzymol. 1995;1247(1):12-6. https://doi.org/10.1016/0167-4838(94)00166-E.

36. Hayashi T, Era S, Kawai K, Imai H, Nakamura K, Onda E, et al. Observation for redox state of human serum and aqueous humor albumin from patients with senile cataract. Pathophysiology. 2000;6(4):237-43. https://doi.org/10.1 016/S0928-4680(99)00022-X.

37. Lee E-H, Kim W-J, Kim J-Y, Chin J-H, Choi D-K, Sim J-Y, et al. Effect of exogenous albumin on the incidence of postoperative acute kidney injury in patients undergoing off-pump coronary artery bypass surgery with a preoperative albumin level of less than $4.0 \mathrm{~g} / \mathrm{dl}$. Anesthesiology. 2016;124(5): 1001-11. https://doi.org/10.1097/ALN.0000000000001051.

38. Kidney Disease: Improving Global Outcomes (KDIGO) Acute Kidney Injury Work Group. KDIGO Clinical Practice Guideline for Acute Kidney Injury. Kidney inter., Suppl. 2012;2:1-138.

39. Harris PA, Taylor R, Minor BL, Elliott V, Fernandez M, O'Neal L, et al. The REDCap consortium: building an international community of software platform partners. J Biomed Inform. 2019;95:103208.

40. Harris PA, Taylor R, Thielke R, Payne J, Gonzalez N, Conde JG. Research electronic data capture (REDCap)--a metadata-driven methodology and workflow process for providing translational research informatics support. J Biomed Inform. 2009;42(2):377-81. https://doi.org/10.1016/j.jbi.2008.08.010.

\section{Publisher's Note}

Springer Nature remains neutral with regard to jurisdictional claims in published maps and institutional affiliations. 